\title{
Ni-Doped Titanium Dioxide Films Obtained by Plasma Electrolytic Oxidation in Refrigerated Electrolytes
}

\author{
Hamed Arab $^{1}$, Gian Luca Chiarello ${ }^{2}{ }^{-}$, Elena Selli ${ }^{2}{ }^{-}$, Giacomo Bomboi ${ }^{1}$, Alberto Calloni ${ }^{3}{ }^{(D}$, \\ Gianlorenzo Bussetti ${ }^{3}$ (-) Guglielmo Albani ${ }^{3}$, Massimiliano Bestetti ${ }^{1,4}$ and Silvia Franz ${ }^{1, *}$ \\ 1 Department of Chemistry, Materials and Chemical Engineering “G. Natta”, Politecnico di Milano, \\ 20133 Milano, Italy; arab.hamed@polimi.it (H.A.); giacomo.bomboi@mail.polimi.it (G.B.); \\ massimiliano.bestetti@polimi.it (M.B.) \\ 2 Department of Chemistry, Università degli Studi di Milano, 20122 Milano, Italy; \\ gianluca.chiarello@unimi.it (G.L.C.); elena.selli@unimi.it (E.S.) \\ 3 Department of Physics, Politecnico di Milano, 20133 Milano, Italy; alberto.calloni@polimi.it (A.C.); \\ gianlorenzo.bussetti@polimi.it (G.B.); guglielmopio.albani@polimi.it (G.A.) \\ 4 Department of Experimental Physics, The Weinberg Research Center, Tomsk Polytechnic University, \\ Lenin Avenue 2a, 634050 Tomsk, Russia \\ * Correspondence: silvia.franz@polimi.it; Tel.: +39-02-23993
}

Received: 25 February 2020; Accepted: 31 March 2020; Published: 17 April 2020

\begin{abstract}
Porous crystalline Ni-doped $\mathrm{TiO}_{2}$ films were produced using DC plasma electrolytic oxidation in refrigerated $\mathrm{H}_{2} \mathrm{SO}_{4}$ aqueous solutions containing $\mathrm{NiSO}_{4}$. The crystalline phase structure consisted of a mixture of anatase and rutile, ranging from $\sim 30$ to $\sim 80 \mathrm{wt} \%$ rutile. The oxide films obtained at low $\mathrm{NiSO}_{4}$ concentration showed the highest photocurrent values under monochromatic irradiation in the UV-vis range, outperforming pure $\mathrm{TiO}_{2}$. By increasing $\mathrm{NiSO}_{4}$ concentration above a threshold value, the photoelectrochemical activity of the films decreased below that of undoped $\mathrm{TiO}_{2}$. Similar results were obtained using cyclic voltammetry upon polychromatic UV-vis irradiation. Glow discharge optical emission spectrometry (GD-OES) analysis evidenced a sulfur signal peaking at the $\mathrm{TiO}_{2} / \mathrm{Ti}$ interface. XPS spectra revealed that oxidized $\mathrm{Ni}^{2+}, \mathrm{S}^{4+}$ and $\mathrm{S}^{6+}$ ions were included in the oxide films. In agreement with photocurrent measurements, photoluminescence (PL) spectra confirmed that less intense PL emission, i.e., a lower electron-hole recombination rate, was observed for Ni-doped samples, though overdoping was detrimental.
\end{abstract}

Keywords: titanium dioxide; plasma electrolytic oxidation; Ni-doping; S-doping; photocurrent; IPCE; photoluminescence; XPS

\section{Introduction}

For several decades the two main drawbacks of titanium dioxide, i.e., its relatively high band gap (3.0-3.2 eV) and low quantum efficiency in photocatalytic reactions, hindered the development of practical applications of photocatalysis. In order to tune the band gap and regulate the electronic activity of $\mathrm{TiO}_{2}$, several strategies have been explored such as sensitization with dyes [1,2] and graphene [3,4], the synthesis of nanocomposites [5,6] and doping using metals [7] or non-metals [8,9].

Nickel is among the metal ions investigated for potential doping of $\mathrm{TiO}_{2}$. Based on the calculated total density of states of pure $\mathrm{TiO}_{2}$ and $\mathrm{Ni}-\mathrm{TiO}_{2}$ with/without oxygen vacancies, $\mathrm{Ni}$ is expected to introduce new defect states within the band-gap and to strengthen the intra-band states generated by intrinsic oxygen vacancies due to hybridization of the Ni $3 \mathrm{~d}$ orbitals with the intrinsic defect states $[10,11]$. Ni-doping also showed enhanced adsorption in the visible region [12] and photocatalytic 
degradation rates under visible light about one order of magnitude higher than pristine $\mathrm{TiO}_{2}$ [13]. Since metal doping affects the photoactivity of $\mathrm{TiO}_{2}$ following a complex function of several features of the dopant, namely, (i) concentration and distribution in the lattice; (ii) the energy level within the lattice; (iii) the d electron configuration; (iv) the electron donor density and the incident light intensity [13], it is reasonable to expect that the specific preparation method has significant impact on the photoactivity of doped $\mathrm{TiO}_{2}$. Ni-doped $\mathrm{TiO}_{2}$ has been prepared in the form of nanotubes obtained using hydrothermal synthesis [14]; in the form of powders using the sol-gel method [15], calcination of oxide mixtures [12] or mechanical alloying [10]; in the form of films using magnetron sputtering [16] and as nanotube arrays using conventional anodization [17].

Plasma electrolytic oxidation (PEO) has seldom been considered for the synthesis of Ni-doped $\mathrm{TiO}_{2}$ layers. The only study focusing on Ni-doping using PEO was proposed by Yao et al. [18], who reported that Ni-doping increases the $\mathrm{H}_{2}$ production rate of $\mathrm{TiO}_{2}$-based catalysts under UV-A irradiation. $\mathrm{PEO}$ was carried out in AC galvanostatic mode in alkaline electrolytes containing nickel acetate as source of Ni. Ni-doping is also briefly mentioned in a work from Xiang et al., where PEO was carried out in phosphate and fluoride-based electrolytes in DC potentiostatic mode at high voltages (330-450 V). It was reported that $\mathrm{Ni}$ was among the metals inducing the highest photocatalytic activity under UV-vis irradiation but no further investigation was carried out on the optical and photoelectrochemical properties of the Ni-doped layers [19].

The relatively poor literature on Ni-doping using PEO is quite surprising considering the promising results reported so far on metal-doping using PEO [19-24], but also the significant industrial impact of PEO [25]. Indeed, PEO can be seen as in between a low voltage conventional anodic oxidation and high-energy plasma coating under dry conditions in controlled gas pressure. Compared to traditional anodizing resulting in $\mathrm{TiO}_{2}$ nanotube arrays [26,27], the PEO process works at higher currents and higher voltages, but also requires a very short processing time (less than $10 \mathrm{~min}$ ), allowing high growth rate (roughly $1 \mu \mathrm{m} \mathrm{min}^{-1}$ ). Furthermore, the high pressure and temperature locally induced by sparking can significantly affect the oxide morphology and crystal structure and composition, promoting instantaneous oxide crystallization [28-30] and incorporation of chemical species from the electrolyte $[25,30-36]$. For these reasons, PEO has been widely applied at the industrial scale for the synthesis of protective coatings on $\mathrm{Mg}$ and $\mathrm{Al}$ alloys, and more recently it was successfully applied to the synthesis of large area electrodes for photo(electro)catalytic water treatment [37-40].

Aiming at exploring the potential of Ni-doping using PEO and considering that PEO operating parameters introduce a great variability on the properties of the obtained layers [28,29], in the present study a systematic investigation of the optical and photoelectrochemical properties of $\mathrm{Ni}$-doped $\mathrm{TiO}_{2}$ layers obtained using PEO is presented.

\section{Materials and Methods}

\subsection{Preparation of $\mathrm{Ni}$-Doped $\mathrm{TiO}_{2}$ Films}

Ni-doped $\mathrm{TiO}_{2}$ films were prepared using PEO of commercially pure (Grade I) titanium sheets (Industrie DeNora S.p.A., Milano, Italy). Prior to PEO, Ti specimens were etched in a dilute HF aqueous solution. PEO was conducted in DC mode at $150 \mathrm{~V}$ for $10 \mathrm{~min}$ processing time. During PEO, the maximum current was set at $10 \mathrm{~A}$. The anode was a titanium sheet with $6 \mathrm{~cm}^{2}$ exposed area, while the cathode was a titanium mesh. The electrolyte consisted of aqueous solutions containing $1.5 \mathrm{M} \mathrm{H}_{2} \mathrm{SO}_{4}$ and 0-0.6 $\mathrm{mM} \mathrm{NiSO}_{4}$, having a total volume of $1 \mathrm{~L}$. During PEO, the electrolyte temperature was set at $-5{ }^{\circ} \mathrm{C}$ by means of a cryostat (HAAKE D10, Thermo Electron Corp., Karlsruhe, Germany). After PEO, the samples were rinsed with water and dried in an air stream. Reference samples consisting of pure anatase and pure rutile were obtained using PEO at a constant voltage of $120 \mathrm{~V}$ and $180 \mathrm{~V}$, respectively. All samples were prepared in duplicate. The obtained films were labeled from S0 to S6 as a function of the $\mathrm{NiSO}_{4}$ concentration in the electrolyte, as specified in Table 1. Similarly, pure anatase and pure rutile samples were labeled as SA and SR, respectively. 
Table 1. Sample labelling, corresponding $\mathrm{NiSO}_{4}$ concentration in the electrolyte, anatase/rutile weight fraction, band-gap energy $\left(\mathrm{E}_{\mathrm{BG}}\right)$, conduction band edge $\left(\mathrm{CB}_{\text {edge }}\right)$.

\begin{tabular}{|c|c|c|c|c|}
\hline Sample & $\mathrm{NiSO}_{4}(\mathrm{mM}) /\left(\mathrm{g} \mathrm{L}^{-1}\right)$ & Anatase/Rutile (wt \%) & $E_{B G}(e V)$ & $\mathrm{CB}_{\text {edge }}\left(\mathrm{V}_{\mathrm{SCE}, \mathrm{pH}=7}\right)$ \\
\hline S0 & $0 / 0$ & $55.1 / 44.9$ & 3.08 & -0.28 \\
\hline S2 & $0.2 / 0.054$ & $66.4 / 33.6$ & 3.09 & -0.31 \\
\hline S4 & $0.4 / 0.1123$ & $60.7 / 39.3$ & 3.10 & -0.23 \\
\hline S6 & $0.6 / 0.1695$ & $18.0 / 82.0$ & 3.06 & -0.23 \\
\hline SA & $0 / 0$ & $100 / 0$ & 3.18 & - \\
\hline SR & $0 / 0$ & $0 / 100$ & 2.94 & - \\
\hline
\end{tabular}

\subsection{Characterization of $\mathrm{TiO}_{2}$ Photoanodes}

The surface morphology of the $\mathrm{TiO}_{2}$ films was investigated using scanning electron microscopy (SEM, EVO 50, Carl Zeiss Jena GmbH, Jena, Germany). Film thickness and in-depth elemental composition were determined using glow discharge optical emission spectrometry (GD-OES) using a Spectrum GDA750 analyzer (SPECTRO Analytical Instruments Inc., Kleve, Germany) operated at $700 \mathrm{~V}$ in argon atmosphere at $230 \mathrm{~Pa}$. Energy-dispersive X-ray spectroscopy (EDX) and X-ray photoemission spectroscopy (XPS) were also carried out to assess the elemental composition. Both techniques are characterized by similar detection limits (in the $0.1-1$ at \% range $[41,42]$ ), nonetheless XPS is a stand-alone tool that provides higher sensitivity and accuracy for the elemental compounds analysis. XPS was performed in a dedicated ultra-high vacuum system (base pressure in the low $10^{-8} \mathrm{~Pa}$ ) by exciting electrons with an Al-K $\alpha$ source $(h v=1486.6 \mathrm{eV})$ and analyzing them with a $150 \mathrm{~mm}$ hemispherical analyzer from SPECS GmbH (Berlin, Germany) [43]. We accounted for possible charging effects by setting the peak from adventitious carbon to $285 \mathrm{eV}$ [44].

$X$-ray diffraction (XRD) patterns were acquired at the scanning rate of $2.5^{\circ} \mathrm{min}^{-1}$ with $\mathrm{CuK}_{\alpha 1}$ radiation in the $20^{\circ}-60^{\circ} 2 \theta$ range by means of a PW1830 diffractometer (Malvern Panalytical Ltd., Malvern, UK and Almelo, The Netherlands) operating at $40 \mathrm{kV}$ voltage and $40 \mathrm{~mA}$ filament current. The XRD patterns were indexed according to the powder diffraction files released by the International Center for Diffraction Data (Newtown, PA, USA) for titanium (PDF 44-1294), anatase (PDF 21-1272) and rutile phases (PDF 21-1276). The weight fraction of anatase $\left(f_{\mathrm{A}}\right)$ was calculated according to Equation (1) [45], where $I_{R}$ is the intensity of the (110) rutile reflection and $I_{\mathrm{A}}$ is the intensity of the (101) anatase reflection.

$$
f_{\mathrm{A}}=\frac{1}{\left(1+1.26 \frac{\left(I_{\mathrm{R}}\right)}{\left(I_{\mathrm{A}}\right)}\right)} \%
$$

UV-vis-NIR diffuse reflectance spectra (DRS) were recorded in the 220-2600 nm range with a UV3600 Plus spectrophotometer from Shimadzu Corp. (Kyoto, Japan) equipped with an ISR-603 integrating sphere. The band gap was calculated based on the UV-vis reflectance spectra after Kubelka-Munk conversion using the Tauc plot method [46].

Photoluminescence (PL) spectra were recorded with an FLS980 spectrofluorometer (Edinburgh Instrument Ltd., Livingston, UK) in the range starting from $20 \mathrm{~nm}$ above the excitation wavelength (300 and $380 \mathrm{~nm}$, respectively) up to $850 \mathrm{~nm}$.

Electrochemical impedance spectroscopy (EIS) measurements were performed in the dark and in 1.0 $\mathrm{M} \mathrm{NaOH}$ aqueous solutions at the open circuit potential (OCP) of each specimen. The amplitude perturbation was $10 \mathrm{mV}$ and the frequency ranged from $300 \mathrm{kHz}$ to $10 \mathrm{mHz}$ using a ModuLab ${ }^{\circledR}$ XM ECS high-performance potentiostat/galvanostat system (Solartron Analytical, XM PSTAT 1 MS/s, Ametek Inc., Berwyn, IL, USA). The instrument was coupled with a frequency response analyzer (Solartron Analytical, XM FRA 1MHz, Ametek Inc., Berwyn, IL, USA) for AC measurements. The EIS 
results were fitted with a Randles-type equivalent circuit with Zview software (Ametek Inc., Berwyn, IL, USA).

The photocurrent density as a function of the irradiation wavelength was measured in a $1.0 \mathrm{M}$ $\mathrm{NaOH}$ aqueous solution using an optical bench equipped with a $300 \mathrm{~W}$ Xe lamp (Quantum Design Europe GmbH, Darmstadt, Germany), a monochromator (Omni- $\lambda$ 150, Quantum Design Europe GmbH, Darmstadt, Germany), a shutter (SC10, Thorlabs Inc., Newton, MA, USA) and a homemade three electrode two compartment Plexiglas cell together with an optical Pyrex glass window. A PEO $\mathrm{TiO}_{2}$ photoelectrode was used as working electrode, and a platinum foil and a saturated calomel electrode (SCE) were used as counter and reference electrodes, respectively. Electrochemical measurements were conducted at room temperature on both biased and unbiased $\mathrm{TiO}_{2}$ photoelectrodes using a 2549 potentiostat/galvanostat from Amel S.r.l. (Milano, Italy) and a DMM4040 digital multimeter from Tektronix (Beaverton, OR, USA). The incident wavelength values ranged from 250 to $450 \mathrm{~nm}$ with a $2 \mathrm{~nm}$ step and a $4 \mathrm{~s}$ per step dwell time. The incident light power was measured using a calibrated Thorlabs S130VC photodiode connected to a PM200 power meter (Thorlabs Inc., Newton, MA, USA) placed at exactly the same distance as the $\mathrm{TiO}_{2}$ electrode, with the Pyrex window in between to account for the transmittance of the cell window. The incident photon-to-current efficiency (IPCE) at each wavelength was calculated using the following Equation:

$$
\operatorname{IPCE}(\%)=\frac{h c}{e} \times \frac{I}{P \lambda}
$$

where $h\left(\mathrm{~kg} \mathrm{~m}^{2} \mathrm{~s}^{-1}\right)$ is the Planck constant, $c\left(\mathrm{~m} \mathrm{~s}^{-1}\right)$ is the speed of light, $e(C)$ is the electron charge, $I\left(\mathrm{~A} \mathrm{~m}^{-2}\right)$ is the steady-state photocurrent density, $P\left(\mathrm{~W} \mathrm{~m}^{-2}\right)$ is the light intensity and $\lambda(\mathrm{m})$ is the incident wavelength.

Linear sweep voltammetry (LSV) was carried out in a three electrodes cell containing $4 \mathrm{mM}$ $\mathrm{KCl}$ aqueous solution. LSV was conducted from -0.5 to $1 \mathrm{~V}$ vs. SCE at a scan rate of $10 \mathrm{mV} \mathrm{s} \mathrm{s}^{-1}$ and room temperature. The working electrode was a titanium dioxide sheet obtained using PEO. The counter electrode was platinum foil, and the reference electrode was a saturated calomel electrode (SCE). The photocurrent was calculated as difference between the current response in the dark and under irradiation, as a function of the polarization potential. For the measurements, a 2549 potentiostat/galvanostat (Amel S.r.l., Milano, Italy) was used. The irradiation was achieved by means of a polychromatic commercial Xenon lamp. The irradiance of the samples was $100 \mathrm{~mW} \mathrm{~cm}^{-2}$, as measured by a calibrated Thorlabs S130VC photodiode connected to a Thorlabs PM200 power meter placed at exactly the same distance as the investigated films. The exposed area during LSV was $5 \mathrm{~cm}^{2}$. All measurements were repeated twice.

\section{Results and Discussion}

\subsection{Morphology and Composition}

Figure 1 shows the SEM micrographs and EDX spectra of sample S0 (Figure 1a) and S6 (Figure 1b). SEM analysis revealed a surface morphology typical of PEO coatings. Indeed, they are homogeneous and porous, the pores having sub-micrometric dimensions and a branched structure. Apparently, the concentration of Ni sulfate in the electrolyte did not affect the morphology of the obtained film. Based on the EDX elemental analysis, the $\mathrm{TiO}_{2}$ films consisted of $\mathrm{Ti}$ and $\mathrm{O}$ elements. No emission from $\mathrm{Ni}$ or $\mathrm{S}$ was detected; however, a very low concentration of these species could not be ruled out.

The GD-OES in-depth composition profiles of samples S0 and S6 are shown in Figure 2a,b, respectively. In addition to the expected signals for titanium and oxygen elements, both samples revealed a signal corresponding to sulfur, peaking in proximity of the $\mathrm{TiO}_{2} / \mathrm{Ti}$ interface. This signal showed a wide tail spreading across the film thickness and barely reached the $\mathrm{TiO}_{2}$ surface. The presence of sulfur can be reasonably ascribed to sulfuric acid contained in the electrolyte, while the shape of the sulfur signal might be reasonably explained by blending of the oxide layer taking place during PEO. 
Indeed, the intense sparking occurring at the operating conditions locally melted the oxide, probably moving sulfur-containing species initially included in the $\mathrm{TiO}_{2}$ film up to the surface of the oxide. Unexpectedly, in sample S6 the Ni element was not detected. Film thickness, as assessed using the GD-OES composition profiles, was $\sim 3.3 \mu \mathrm{m}$ regardless of the Ni concentration in the electrolyte.
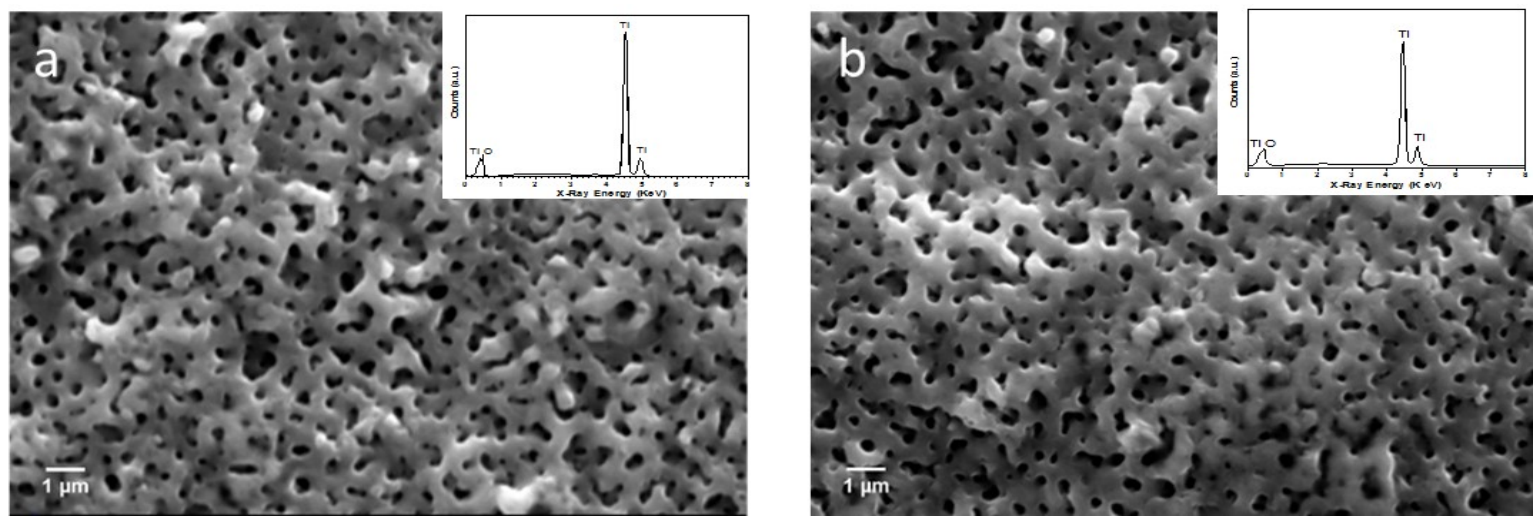

Figure 1. Scanning electron microscopy (SEM) micrographs and energy-dispersive X-ray spectroscopy (EDX) analysis (inset) of sample (a) S0 and (b) S6.

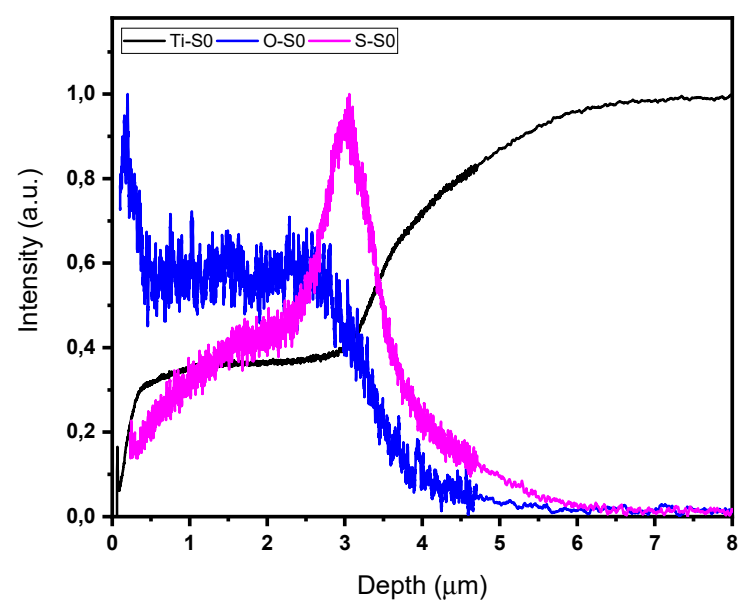

(a)

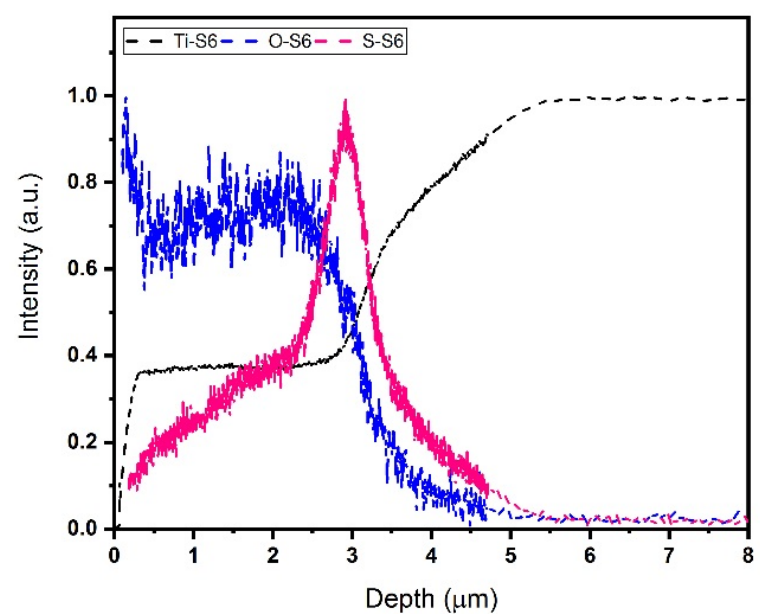

(b)

Figure 2. Glow discharge optical emission spectrometry (GD-OES) in-depth analysis for sample (a) S0 and (b) S6.

A more detailed elemental investigation was performed using XPS. The survey scans of samples $\mathrm{S} 0$ and $\mathrm{S} 6$ are shown in Figure 3a, where the binding energy (BE) position of photoemission signals from $\mathrm{Ni}, \mathrm{O}, \mathrm{Ti}, \mathrm{C}$ and $\mathrm{S}$ is also highlighted. The observed $\mathrm{C}$ 1s signal is attributed to adventitious carbon. The $\mathrm{BE}$ position of $\mathrm{O} 1 s$ and Ti $2 \mathrm{p}_{3 / 2}$ peaks is consistent with the values reported in the literature for $\mathrm{TiO}_{2}[47,48]$. The presence of $\mathrm{Ni}$ in sample $\mathrm{S} 6$ is testified by the detection of a small photoemission signal from the Ni $2 p_{3 / 2}$ orbital, as shown in the detailed scan of Figure $3 \mathrm{~b}$. The BE position of the $\mathrm{Ni}$ feature (about $856 \mathrm{eV}$ ) is typical of oxidized $\mathrm{Ni}^{2+}$ species [16]. As shown in the inset of Figure 3d, the intensity of photoemission signal from Ni 2 $\mathrm{p}_{3 / 2}$ increases in the order $\mathrm{S} 0<\mathrm{S} 2<\mathrm{S} 4<\mathrm{S} 6$, thus demonstrating that the concentration of $\mathrm{NiSO}_{4}$ impacts on the amount of $\mathrm{Ni}$ ions included in the oxide films. The $S 2 p$ region (Figure 3c) shows a feature located at a BE of about $169 \mathrm{eV}$, which is compatible with the presence of photoemission signals from both tetravalent $\mathrm{S}^{4+}$ and hexavalent $\mathrm{S}^{6+}$ sulfur (at the very close $\mathrm{BE}$ of $168.8 \mathrm{eV}$ and $169.5 \mathrm{eV}$, respectively), as also reported in literature [49]. Considering these two possible contributions, the strongest peak at $169.5 \mathrm{eV}$ is usually assigned to $\mathrm{SO}_{4}{ }^{2-}$ groups adsorbed on the $\mathrm{TiO}_{2}$ surface [50]. This assignment is reasonable in the present case, 
considering that PEO of titanium was carried out in sulfuric acid solutions. As for the tetravalent sulfur signal, $\mathrm{S}^{4+}$ species can be incorporated into $\mathrm{TiO}_{2}$ either interstitially or at the $\mathrm{Ti}^{4+}$ lattice site [51].

(a)

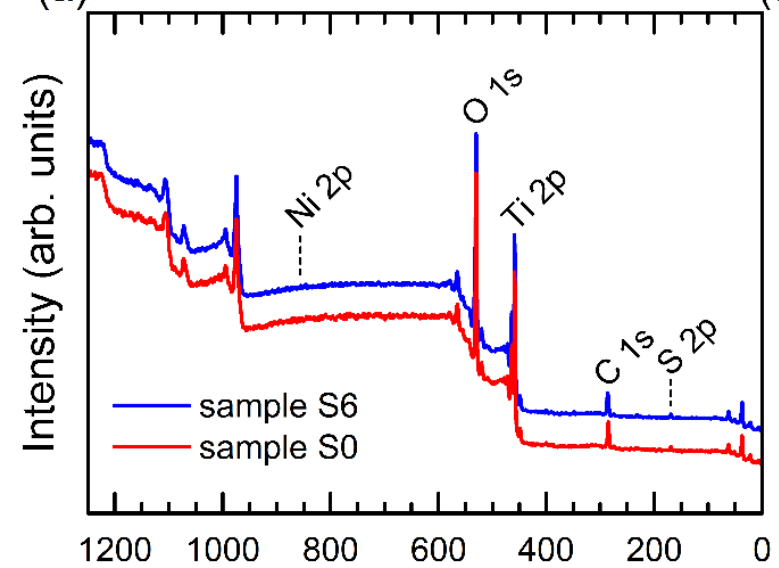

(b)

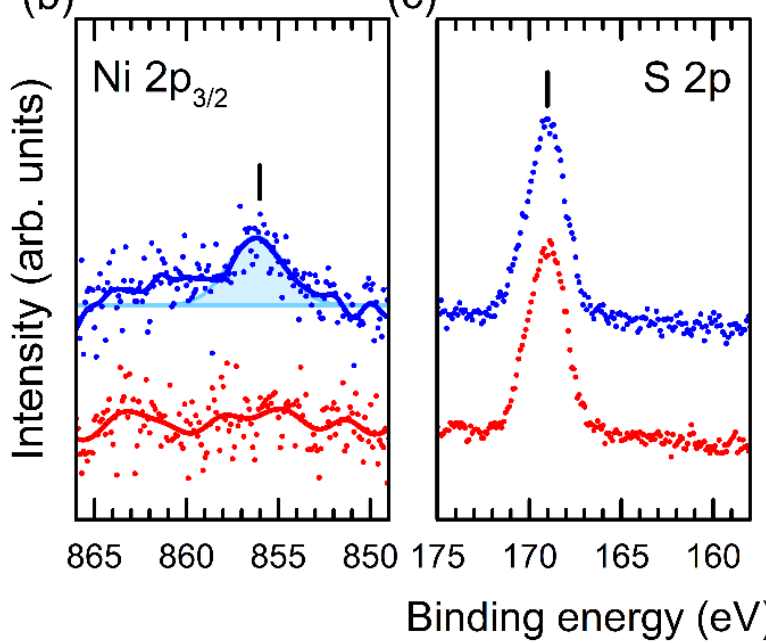

(d)

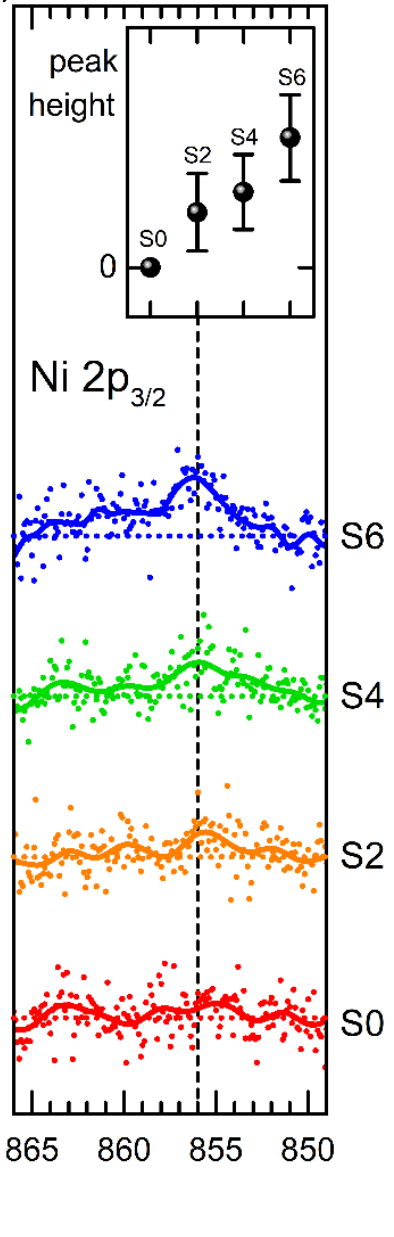

Figure 3. XPS spectra taken from samples S0 (red) and S6 (blue): (a) wide scans; (b,c) detailed scans of the $\mathrm{Ni} 2 \mathrm{p}_{3 / 2}$ and $\mathrm{S} 2 \mathrm{p}$ binding energy regions. The photoemission signal from $\mathrm{Ni}$ is highlighted in panel (b) by fitting a peak function to the experimental data. (d) XPS spectra taken from samples S0 (red), S2 (orange), S4 (green) and S6 (blue) and Ni peak height as a function of the Ni concentration. The spectra of panels (b) and (d), shown after the subtraction of a linear background, have been additionally smoothed to enhance the visibility of the Ni line shape. Spectra from different samples are vertically offset for clarity.

Electrochemical impedance spectroscopy tests were carried out to investigate the electrochemical properties of the oxide films. The resulting Nyquist plots shown in Figure 4 exhibit a typical semicircle shape. The semicircle obtained for sample S2 is smaller than that recorded for samples S0, S4 and S6, suggesting lower charge transfer resistance allowing a more efficient transport and separation of electron-hole pairs. 


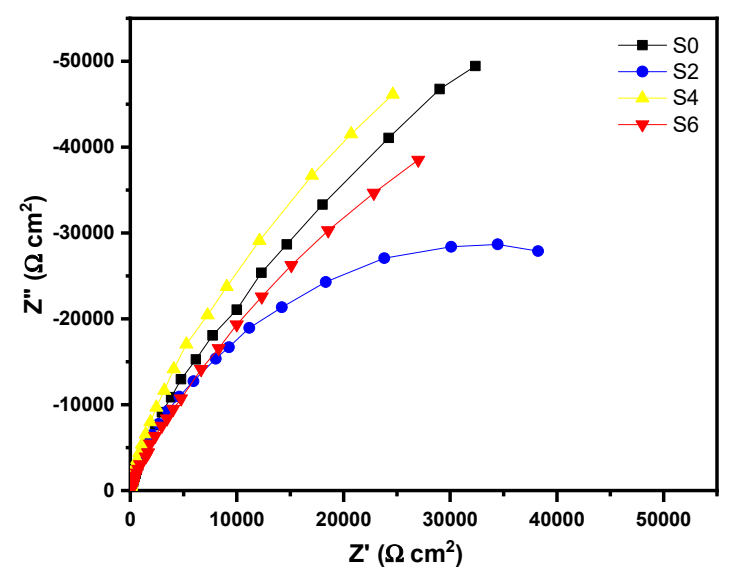

Figure 4. Nyquist plots of experimental (symbols) and fitted (lines) data for samples S0, S2, S4 and S6.

\subsection{Crystal Structure and Band-Gap Determination}

XRD results on doped and undoped $\mathrm{TiO}_{2}$ films are shown in Figure $5 \mathrm{a}$. The $\mathrm{TiO}_{2}$ films were mainly crystalline in structure and consisted of a mixture of anatase and rutile allotropic phases, even though the presence of a minor amorphous component in the $\mathrm{TiO}_{2}$ film structure cannot be completely ruled out. The XRD peaks at $2 \theta \approx 25.31^{\circ}, 48.06^{\circ}$ and $55.11^{\circ}$ were attributed to the anatase phase, those at $2 \theta \approx 27.44^{\circ}, 36.09^{\circ}, 41.26^{\circ}$ and $54.33^{\circ}$ to the rutile phase, and finally those at $2 \theta \approx 35.06^{\circ}, 38.40^{\circ}, 40.17^{\circ}$ and $53.01^{\circ}$ to the Ti substrate. No Ni-containing phases were detected in the PEO layers. As shown in Figure A1 (Appendix A), no lattice distortion was observed by increasing the $\mathrm{NiSO}_{4}$ concentration. Indeed, substitutional $\mathrm{Ni}$ ions at $\mathrm{Ti}^{4+}$ sites are not expected to induce lattice distortion as they have similar ionic radii, i.e., 0.61 and $0.69 \AA$ for $\mathrm{Ti}^{4+}$ and $\mathrm{Ni}^{2+}$, respectively. In agreement with literature, at the highest nickel sulfate concentration (S6) the rutile reflections centered at $2 \theta \approx 27.44^{\circ}$ and 36.09 became stronger, indicating that a higher Ni-doping favors the formation of the rutile phase [15]. The weight percentage of anatase and rutile phases obtained using Equation (1) is reported in Table 1. The rutile percentage increased from $\sim 30 \%$ to $\sim 80 \%$ at increasing nickel sulfate concentration. Figure $5 \mathrm{~b}$ shows the UV-vis-NIR diffuse reflectance spectra of the investigated samples as Tauc-plots of the Kubelka-Munk transform. As expected, the calculated band-gap values reported in Table 1 are in good agreement with the corresponding phase composition.

\subsection{Photocurrent and IPCE}

Figure A2 shows the photocurrent density values measured for all samples as a function of the irradiation wavelength and under a $0.6 \mathrm{~V}$ vs. SCE applied bias. The corresponding light power is also reported on the right $y$-axis of the same figure. The corresponding IPCE curves calculated using Equation (2) are plotted in Figure 6a. The investigated samples exhibit a bimodal curve. According to literature [52,53], the absorption peaks around 325 and $380 \mathrm{~nm}$ can be attributed to the anatase and rutile phases, respectively. Thus, in the present case the curve shapes and the relative intensity of the two maxima well reflect the crystalline structure of the films. The highest IPCE values were observed for sample S2, reaching 55\% depending on the irradiation wavelength. Samples S0 and S4 showed very similar IPCE values, while the lowest values were measured for S6, which mainly consisted of rutile phase. The photocurrent onset is below $414 \mathrm{~nm}$, in partial agreement with the calculated band gap reported in Table 1. 

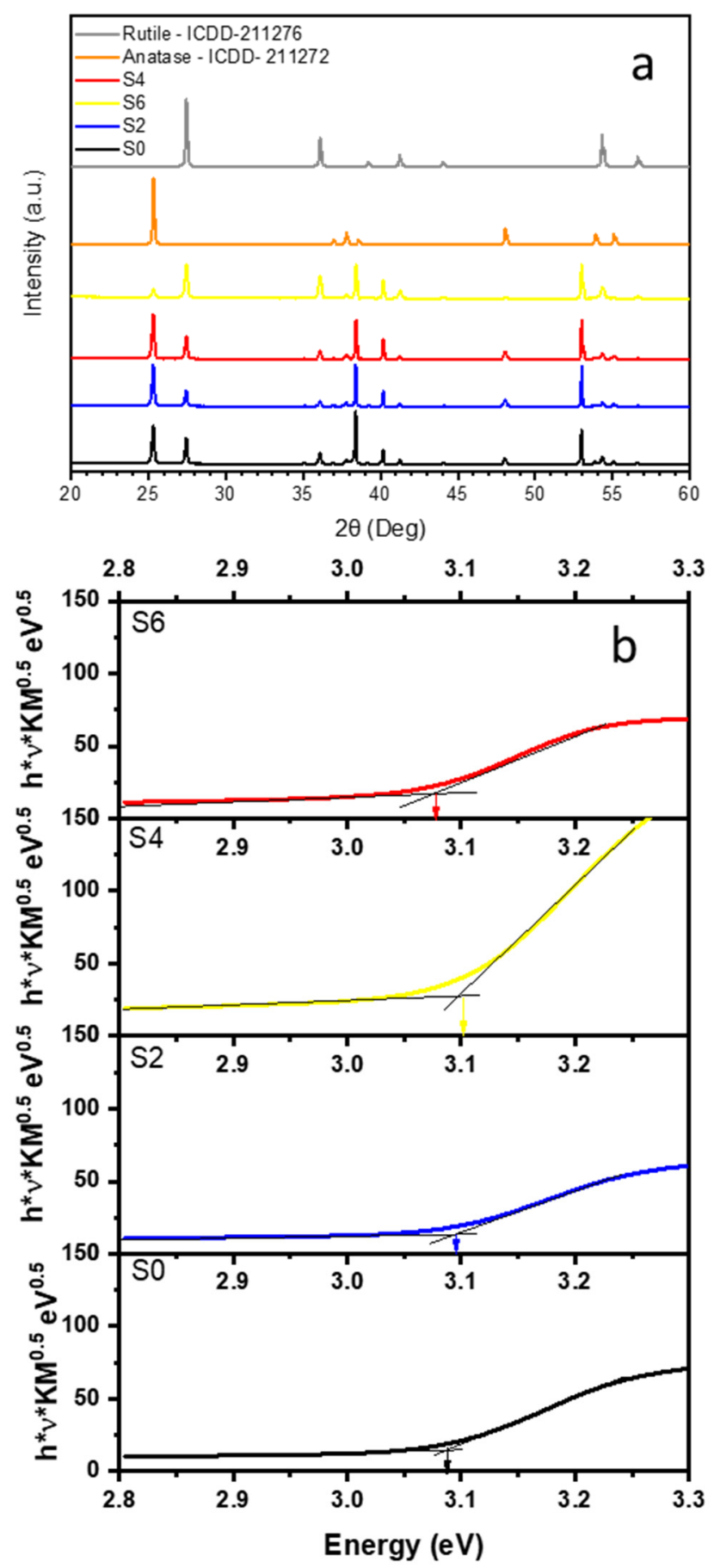

Figure 5. (a) XRD pattern of samples S0, S2, S4 and S6 obtained at various nickel sulfate concentrations in the electrolyte. (b) UV-vis-NIR diffuse reflectance spectra (DRS) for some representative $\mathrm{TiO}_{2}$ samples as Tauc-plots of the Kubelka-Munk transform.

LSV curves recorded from -0.5 to $1 \mathrm{~V}$ vs. SCE under continuous Xenon light irradiation are shown in Figure 6b. LSV tests were repeated twice and good reproducibility was assessed. Comparing the LSV results of all samples, three main considerations can be made: (i) in agreement with the IPCE data reported in Figure 6a the maximum photocurrent density decreased following the order S2 > S4 > S0 > S6; (ii) only S0 and S6 reached photocurrent saturation; (iii) the photocurrent potential onset shifted towards more positive values for Ni-doped $\mathrm{TiO}_{2}$ films compared to undoped films, except for sample $\mathrm{S} 2$. The $\mathrm{CB}_{\text {edge }}$ values were $-0.28 \mathrm{~V}_{\mathrm{SCE}, \mathrm{pH}=7}$ in $\mathrm{S} 0,-0.31 \mathrm{~V}_{\mathrm{SCE}, \mathrm{pH}=7}$ in $\mathrm{S} 2,-0.23 \mathrm{~V}_{\mathrm{SCE}, \mathrm{pH}=7}$ in

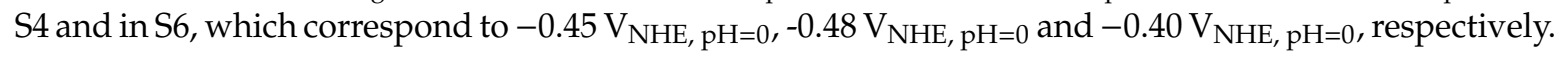


As the potential onset is representative of the conduction band edge energy, the shift towards more positive values (i.e., lower energies) would partially account for the correspondingly smaller band-gap energy values.
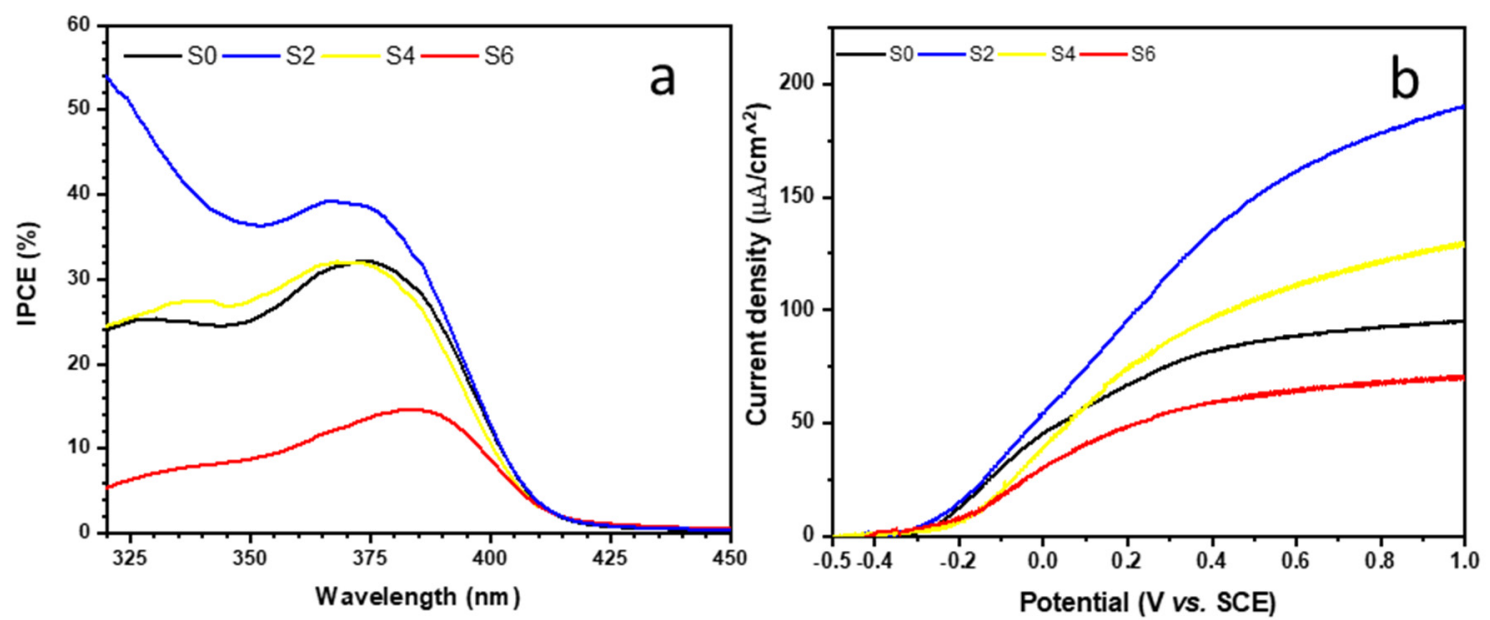

Figure 6. (a) Incident photon-to-current efficiency (IPCE) vs. irradiation wavelength curves and (b) linear sweep voltammetry (LSV) curves recorded from -0.5 to $1 \mathrm{~V}$ vs. SCE at $5 \mathrm{mV} \mathrm{s}^{-1}$ upon continuous Xenon light irradiation, measured for samples S0, S2, S4 and S6.

Overall, S2 shows a better photocurrent response, both as a function of the irradiation wavelength and under continuous polychromatic irradiation. In addition to the optimum crystalline phase composition, this might also be partially attributed to the lower charge transfer resistance estimated on the basis of the Nyquist curves shown in Figure 4.

\subsection{Photoluminescence Spectroscopy}

In order to achieve a better insight on the effectiveness of trapping, migration and transfer of charge carriers in the investigated films, the photoluminescence (PL) spectra of some representative samples were acquired upon excitation at $300 \mathrm{~nm}$. They are reported in Figure 7a, together with the spectra of $\mathrm{PEO} \mathrm{TiO}_{2}$ films consisting in either pure anatase or almost pure rutile. The first emission peak at $354 \mathrm{~nm}(3.51 \mathrm{eV})$, observed for all samples, can be attributed to direct recombination with holes of hot electrons excited in the conduction band (CB), i.e., electrons not fully relaxed to the bottom of the CB. The second peak at $388 \mathrm{~nm}(3.19 \mathrm{eV})$ reflects the recombination between electrons at the bottom of the $\mathrm{CB}$ and holes in the valence band (VB) of the anatase phase and was detected for all samples, in agreement with the crystalline phase composition. The other emission signals must be necessarily ascribed to electronic transitions involving intra-band energy states. The peak at $\sim 555 \mathrm{~nm}(2.23 \mathrm{eV})$ measured for all samples with the exception of sample $S R$, might be tentatively attributed to a transition from the $C B$ to mid-gap states corresponding to oxygen vacancies generated by the replacement of $S^{6+}$ for $\mathrm{Ti}^{4+}$ [54]. The broad emission band observed between 400 and $\sim 700 \mathrm{~nm}$ (i.e., $3.10 \mathrm{eV} \div 1.77 \mathrm{eV}$ ) can be attributed to oxygen vacancies and/or defects. In fact, oxygen vacancies and defects can bind the electrons photoexcited in the CB to form excitons, thus increasing the PL emission [55].

However, based on first-principle band calculations, the presence in the same region of additional intra-band states due to $\mathrm{Ti}_{1-\mathrm{x}} \mathrm{S}_{\mathrm{x}} \mathrm{O}_{2}$ deriving from substitutional tetravalent $\mathrm{S}^{4+}$ species cannot be ruled out [56]. S-doping involving both $\mathrm{S}^{6+}$ and $\mathrm{S}^{4+}$ species would also be in agreement with the XPS scans shown in Figure 3. According to DFT calculations reported in literature, Ni-doping also induces intra-band Ni $3 \mathrm{~d}$ states generated by hybridization with the $\mathrm{O} 2 \mathrm{p}$ orbitals [57]. Ni ions can be included in the oxide lattice sites as a substitutional defect, either as $\mathrm{Ni}^{2+}$ or as $\mathrm{Ni}^{3+}$, where $\mathrm{Ni}^{2+}$ can introduce donor levels above the VB, while $\mathrm{Ni}^{3+}$ can trap photopromoted electrons [12]. The PL intensity of sample $\mathrm{S} 2$ is significantly lower than that of the undoped $\mathrm{TiO}_{2}$ film, while the contrary was obtained 
for sample S6. This confirms that doping can effectively suppress the recombination of photogenerated electrons and holes tentatively due to a better oxide stoichiometry, though above a certain threshold value it can have a detrimental effect probably due to charge unbalance [58].
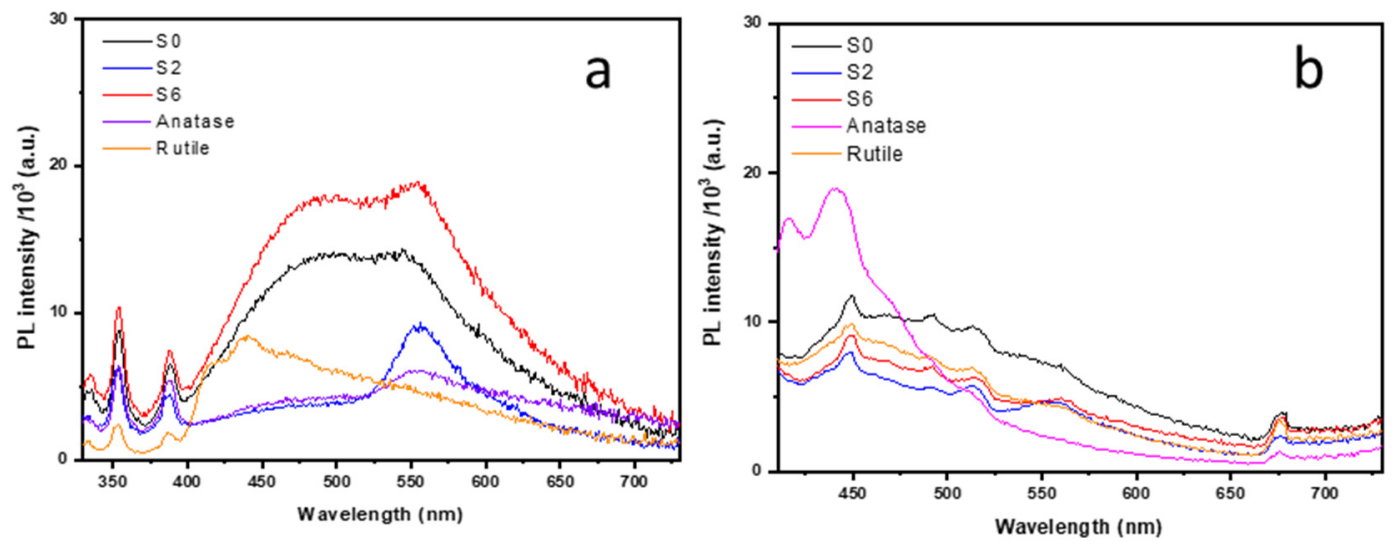

Figure 7. Photoluminescence (PL) spectra of some representative samples (S0, S2 and S6) and samples consisting of anatase phase (SA) and rutile phase (SR), obtained upon excitation at (a) $300 \mathrm{~nm}$ and (b) $380 \mathrm{~nm}$.

PL emission spectra acquired upon irradiation at $380 \mathrm{~nm}$ are also reported (Figure $7 \mathrm{~b}$ ). In this case it is even clearer that by Ni-doping the PL emission decreased with respect to pure $\mathrm{TiO}_{2}$ and that overdoping (sample S6) was somehow detrimental. This is in agreement with literature [59], where it is reported that an excess of dopant corresponds to an excess of structure defects which can play a detrimental role in favoring the undesired electron-hole recombination process.

It is well-known that the PL emission results from the recombination of excited electrons and holes and that high PL intensity corresponds to a high recombination rate. Interestingly, the PL results are in good agreement with the IPCE data reported in Figure 6a. Indeed, higher photocurrent is expected for films showing lower PL emission, i.e., lower electron-hole recombination rate. In the case of the investigated $\mathrm{TiO}_{2}$ films, the optimum doping can be obtained with $0.2 \mathrm{mM} \mathrm{NiSO}_{4}$ in the electrolytic bath.

\section{Conclusions}

Crystalline Ni-doped $\mathrm{TiO}_{2}$ films were successfully obtained using PEO carried out in DC mode in refrigerated electrolytes containing $1.5 \mathrm{M} \mathrm{H}_{2} \mathrm{SO}_{4}$ and $\mathrm{NiSO}_{4}$ in the $0-0.6 \mathrm{mM}$ range, as a source of nickel. The oxide showed a branched and sub-micrometric porous surface morphology, typical of PEO oxides. The as-prepared oxides were crystalline and mainly consisted of a mixture of anatase and rutile. By adding $\mathrm{NiSO}_{4}$ to the electrolytic bath, the relative amount of anatase was initially only marginally affected and not correlated to the electrolyte composition, although at the highest $\mathrm{NiSO}_{4}$ concentration value a clear stabilization of the rutile phase occurred. In addition to the expected oxygen and titanium signals, GD-OES in-depth profile analysis revealed a sulfur signal peaking in proximity of the $\mathrm{TiO}_{2} / \mathrm{Ti}$ interface. XPS analysis demonstrated that S-containing species consisted of both substitutional $\mathrm{S}^{4+}$ ions and $\mathrm{S}^{6+}$ ions, probably due to $\mathrm{SO}_{4}{ }^{2-}$ adsorbed groups. XPS analysis also evidenced the presence of oxidized $\mathrm{Ni}^{2+}$ ions, the intensity of the corresponding photoemission signal increasing with the $\mathrm{NiSO}_{4}$ concentration in the electrolytic bath. Photocurrent measured as a function of the irradiation wavelength showed a bimodal shape peaking at 320 and $375 \mathrm{~nm}$, in agreement with the phase composition. The photocurrent values varied depending on the concentration of $\mathrm{NiSO}_{4}$ in the electrolytic bath, exceeding those of pure $\mathrm{TiO}_{2}$ at the lowest $\mathrm{NiSO}_{4}$ concentration. Maximum IPCE values of $55 \%$ were calculated for $0.2 \mathrm{mM} \mathrm{NiSO}_{4}$. Similar photocurrent results were obtained under UV-vis polychromatic irradiation, where the saturation photocurrent increased with respect to bare $\mathrm{TiO}_{2}$ by addition of $\mathrm{NiSO}_{4}$, with the only exception being the highest concentration. Photoluminescence 
spectra confirmed that doped oxides developing the highest photocurrent values were also less photoluminescent, i.e., they were characterized by lower electron-hole recombination rates. Therefore, provided that $\mathrm{NiSO}_{4}$ is kept below a certain threshold value, Ni-doping using DC PEO increases the photoactivity of the oxide under UV-vis irradiation with respect to undoped $\mathrm{TiO}_{2}$.

Author Contributions: Conceptualization S.F.; formal analysis H.A., G.L.C., A.C. and G.B. (Gianlorenzo Bussetti); investigation H.A., G.L.C., G.B. (Giacomo Bomboi), A.C., G.B. (Gianlorenzo Bussetti) and G.A.; resources M.B and E.S.; supervision S.F., M.B., G.L.C. and E.S.; writing-original drat S.F.; writing-reviewing/editing E.S. and M.B. All authors have read and agreed to the published version of the manuscript.

Funding: This research was partially funded by the MIUR PRIN 2015K7FZLH SMARTNESS project and the MIUR PRIN 20173397R7 MULTI-e project.

Acknowledgments: The use of instrumentation purchased through the SmartMatLab project, Fondazione Cariplo grant 2013-1766, is gratefully acknowledged.

Conflicts of Interest: The authors declare no conflicts of interest.

\section{Appendix A}

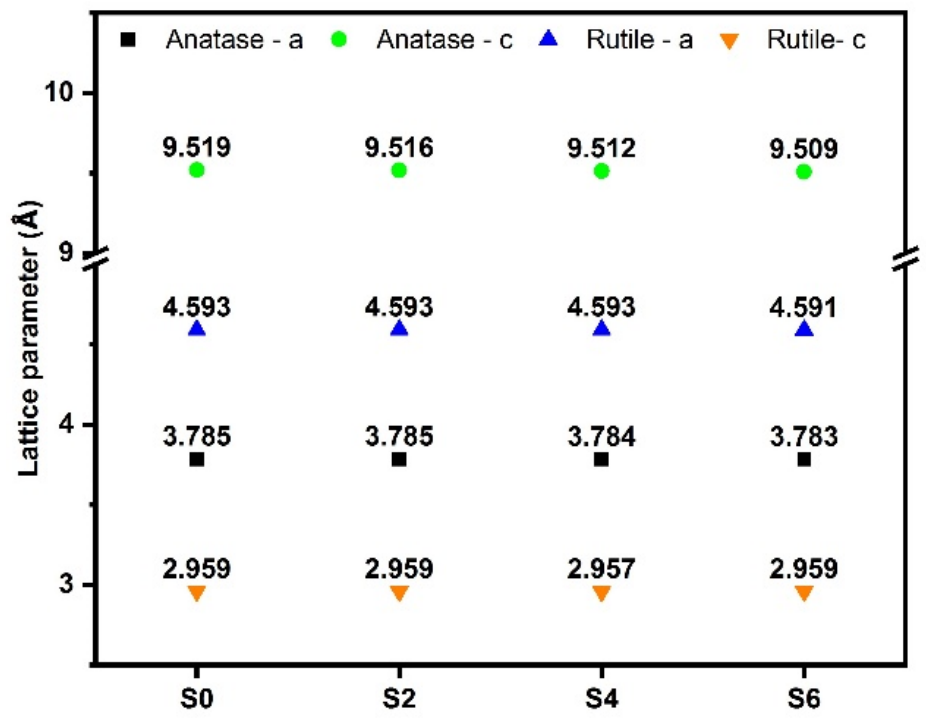

Figure A1. Lattice parameters a and c of the anatase and rutile phases for samples S0, S2, S4 and S6.

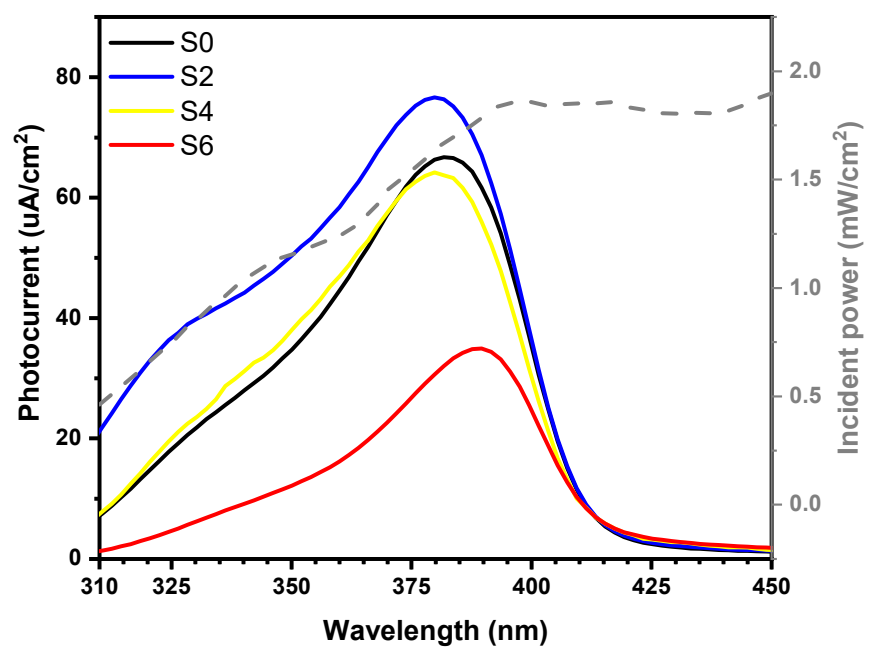

Figure A2. Photocurrent vs. irradiation wavelength curves measured for samples S0, S2, S4 and S6 (left ordinate axis) and corresponding light power (right ordinate axis). 


\section{References}

1. Brady, M.D.; Sampaio, R.N.; Wang, D.; Meyer, T.J.; Meyer, G.J. Dye-Sensitized Hydrobromic Acid Splitting for Hydrogen Solar Fuel Production. J. Am. Chem. Soc. 2017, 139, 15612-15615. [CrossRef] [PubMed]

2. Jaafar, S.N.H.; Minggu, L.J.; Arifin, K.; Kassim, M.B.; Wan, W.R.D. Natural dyes as $\mathrm{TIO}_{2}$ sensitizers with membranes for photoelectrochemical water splitting: An overview. Renew. Sustain. Energy Rev. 2017, 78, 698-709. [CrossRef]

3. Lang, Q.; Chen, Y.; Huang, T.; Yang, L.; Zhong, S.; Wu, L.; Chen, J.; Bai, S. Graphene “bridge" in transferring hot electrons from plasmonic $\mathrm{Ag}$ nanocubes to $\mathrm{TiO}_{2}$ nanosheets for enhanced visible light photocatalytic hydrogen evolution. Appl. Catal. B Environ. 2018, 220, 182-190. [CrossRef]

4. Lu, Y.; Ma, B.; Yang, Y.; Huang, E.; Ge, Z.; Zhang, T.; Zhang, S.; Li, L.; Guan, N.; Ma, Y.; et al. High activity of hot electrons from bulk 3D graphene materials for efficient photocatalytic hydrogen production. Nano Res. 2017, 10, 1662-1672. [CrossRef]

5. Mulewa, W.; Tahir, M.; Amin, N.A.S. MMT-supported $\mathrm{Ni} / \mathrm{TiO}_{2}$ nanocomposite for low temperature ethanol steam reforming toward hydrogen production. Chem. Eng. J. 2017, 326, 956-969. [CrossRef]

6. Xing, X.; Zhang, M.; Hou, L.; Xiao, L.; Li, Q.; Yang, J. Z-scheme BCN-TiO 2 nanocomposites with oxygen vacancy for high efficiency visible light driven hydrogen production. Int. J. Hydrog. Energy 2017, 42, 28434-28444. [CrossRef]

7. Kumaravel, V.; Mathew, S.; Bartlett, J.; Pillai, S.C. Photocatalytic hydrogen production using metal doped TiO2: A review of recent advances. Appl. Catal. B Environ. 2019, 244, 1021-1064. [CrossRef]

8. Dozzi, M.V.; Selli, E. Doping $\mathrm{TiO}_{2}$ with p-block elements: Effects on photocatalytic activity. J. Photochem. Photobiol. C Photochem. Rev. 2013, 14, 13-28. [CrossRef]

9. Di Valentin, C.; Pacchioni, G. Trends in non-metal doping of anatase $\mathrm{TiO}_{2}$ : B, C, N and F. Catal. Today 2013, 206, 12-18. [CrossRef]

10. Hyun Kim, D.; Sub Lee, K.; Kim, Y.-S.; Chung, Y.-C.; Kim, S.-J. Photocatalytic Activity of Ni 8 wt $\%$-Doped $\mathrm{TiO}_{2}$ Photocatalyst Synthesized by Mechanical Alloying Under Visible Light. J. Am. Ceram. Soc. 2006, 89, 515-518. [CrossRef]

11. Gao, L.; Li, Y.; Ren, J.; Wang, S.; Wang, R.; Fu, G.; Hu, Y. Passivation of defect states in anatase $\mathrm{TiO}_{2}$ hollow spheres with $\mathrm{Mg}$ doping: Realizing efficient photocatalytic overall water splitting. Appl. Catal. B Environ. 2017, 202, 127-133. [CrossRef]

12. Niishiro, R.; Kato, H.; Kudo, A. Nickel and either tantalum or niobium-codoped $\mathrm{TiO}_{2}$ and $\mathrm{SrTiO}_{3}$ photocatalysts with visible-light response for $\mathrm{H}_{2}$ or $\mathrm{O}_{2}$ evolution from aqueous solutions. Phys. Chem. Chem. Phys. 2005, 7, 2241-2245. [CrossRef] [PubMed]

13. Choi, J.; Park, H.; Hoffmann, M.R. Effects of single metal-ion doping on the visible-light photoreactivity of $\mathrm{TiO}_{2}$. J. Phys. Chem. C 2010, 114, 783-792. [CrossRef]

14. Shaban, M.; Ahmed, A.M.; Shehata, N.; Betiha, M.A.; Rabie, A.M. Ni-doped and Ni/Cr co-doped TiO 2 nanotubes for enhancement of photocatalytic degradation of methylene blue. J. Colloid Interface Sci. 2019, 555, 31-41. [CrossRef] [PubMed]

15. Manzoor, M.; Rafiq, A.; Ikram, M.; Nafees, M.; Ali, S. Structural, optical, and magnetic study of Ni-doped $\mathrm{TiO}_{2}$ nanoparticles synthesized by sol-gel method. Int. Nano Lett. 2018, 8, 1-8. [CrossRef]

16. Macovei, D.; Tiron, V.; Adomnitei, C.; Luca, D.; Dobromir, M.; Antohe, S.; Mardare, D. On the hydrophilicity of Ni-doped $\mathrm{TiO}_{2}$ thin films. A study by X-ray absorption spectroscopy. Thin Solid Films 2018, 657, 42-49. [CrossRef]

17. Dong, Z.; Ding, D.; Li, T.; Ning, C. Ni-doped $\mathrm{TiO}_{2}$ nanotubes photoanode for enhanced photoelectrochemical water splitting. Appl. Surf. Sci. 2018, 443, 321-328. [CrossRef]

18. Yao, Z.; Jia, F.; Tian, S.; Li, C.; Jiang, Z.; Bai, X. Microporous Ni-Doped $\mathrm{TiO}_{2}$ film photocatalyst by plasma electrolytic oxidation. ACS Appl. Mater. Interfaces 2010, 2, 2617-2622. [CrossRef]

19. Xiang, N.; Zhuang, J.J.; Song, R.G.; Xiang, B.; Xiong, Y.; Su, X.P. Fabrication and photocatalytic activity of $\mathrm{MAO}-\mathrm{TiO}_{2}$ films formed on titanium doped with cations. Mater. Technol. 2016, 31, 332-336. [CrossRef]

20. Soejima, T.; Yagyu, H.; Ito, S. One-pot synthesis and photocatalytic activity of Fe-doped $\mathrm{TiO}_{2}$ films with anatase-rutile nanojunction prepared by plasma electrolytic oxidation. J. Mater. Sci. 2011, 46, 5378-5384. [CrossRef] 
21. Yao, Z.; Jia, F.; Jiang, Y.; Li, C.; Jiang, Z.; Bai, X. Photocatalytic reduction of potassium chromate by Zn-doped $\mathrm{TiO}_{2} /$ Ti film catalyst. Appl. Surf. Sci. 2010, 256, 1793-1797. [CrossRef]

22. Stojadinović, S.; Tadić, N.; Radić, N.; Grbić, B.; Vasilić, R. Effect of $\mathrm{Tb}^{3+}$ doping on the photocatalytic activity of $\mathrm{TiO}_{2}$ coatings formed by plasma electrolytic oxidation of titanium. Surf. Coatings Technol. 2018, 337, 279-289. [CrossRef]

23. Bayati, M.R.; Molaei, R.; Golestani-Fard, F. Enhancing photoinduced hydrophilicity of micro arc oxidized $\mathrm{TiO}_{2}$ nanostructured porous layers by V-doping. Colloids Surf. A Physicochem. Eng. Asp. 2011, 373, 51-60. [CrossRef]

24. Vasilić, R.; Stojadinović, S.; Radić, N.; Stefanov, P.; Dohčević-Mitrović, Z.; Grbić, B. One-step preparation and photocatalytic performance of vanadium doped $\mathrm{TiO}_{2}$ coatings. Mater. Chem. Phys. 2015, 151, 337-344. [CrossRef]

25. Yerokhin, A.L.; Nie, X.; Leyland, A.; Matthews, A.; Dowey, S.J. Plasma Electrolysis for Surface Engineering. Surf. Coat. Technol. 1999, 122, 73-93. [CrossRef]

26. Bestetti, M.; Franz, S.; Cuzzolin, M.; Arosio, P.; Cavallotti, P.L. Structure of nanotubular titanium oxide templates prepared by electrochemical anodization in $\mathrm{H}_{2} \mathrm{SO}_{4} / \mathrm{HF}$ solutions. Thin Solid Films 2007, 515, 5253-5258. [CrossRef]

27. Eskandarloo, H.; Hashempour, M.; Vicenzo, A.; Franz, S.; Badiei, A.; Behnajady, M.A.; Bestetti, M. High-temperature stable anatase-type $\mathrm{TiO}_{2}$ nanotube arrays: A study of the structure-activity relationship. Appl. Catal. B Environ. 2016, 185, 119-132. [CrossRef]

28. Franz, S.; Perego, D.; Marchese, O.; Lucotti, A.; Bestetti, M. Photoactive $\mathrm{TiO}_{2}$ coatings obtained by Plasma Electrolytic Oxidation in refrigerated electrolytes. Appl. Surf. Sci. 2016, 385, 498-505. [CrossRef]

29. Franz, S.; Arab, H.; Lucotti, A.; Castiglioni, C.; Vicenzo, A.; Morini, F.; Bestetti, M. Exploiting Direct Current Plasma Electrolytic Oxidation to Boost Photoelectrocatalysis. Catalysts 2020, 10, 325. [CrossRef]

30. Mirelman, L.K.; Curran, J.A.; Clyne, T.W. The production of anatase-rich photoactive coatings by plasma electrolytic oxidation. Surf. Coat. Technol. 2012, 207, 66-71. [CrossRef]

31. Sundararajan, G.; Rama Krishna, L. Mechanisms underlying the formation of thick alumina coatings through the MAO coating technology. Surf. Coat. Technol. 2003, 167, 269-277. [CrossRef]

32. Bayati, M.R.; Moshfegh, A.Z.; Golestani-Fard, F. In situ growth of vanadia-titania nano/micro-porous layers with enhanced photocatalytic performance by micro-arc oxidation. Electrochim. Acta 2010, 55, 3093-3102. [CrossRef]

33. He, J.; Cai, Q.Z.; Ji, Y.G.; Luo, H.H.; Li, D.J.; Yu, B. Influence of fluorine on the structure and photocatalytic activity of $\mathrm{TiO}_{2}$ film prepared in tungstate-electrolyte via micro-arc oxidation. J. Alloys Compd. 2009, 482, 476-481. [CrossRef]

34. Li, J.F.; Wan, L.; Feng, J.Y. Study on the preparation of titania films for photocatalytic application by micro-arc oxidation. Sol. Energy Mater. Sol. Cells 2006, 90, 2449-2455. [CrossRef]

35. Wu, X.; Ding, X.; Qin, W.; He, W.; Jiang, Z. Enhanced photo-catalytic activity of $\mathrm{TiO}_{2}$ films with doped La prepared by micro-plasma oxidation method. J. Hazard. Mater. 2006, 137, 192-197. [CrossRef]

36. Wu, X.; Wei, Q.; Zhaohua, J. Influence of $\mathrm{Fe}^{3+}$ ions on the photocatalytic activity of $\mathrm{TiO}_{2}$ films prepared by micro-plasma oxidation method. Thin Solid Films 2006, 496, 288-292. [CrossRef]

37. Franz, S.; Perego, D.; Marchese, O.; Bestetti, M. Photoelectrochemical advanced oxidation processes on nanostructured $\mathrm{TiO}_{2}$ catalysts: Decolorization of a textile azo-dye. J. Water Chem. Technol. 2015, 37, 108-115. [CrossRef]

38. Murgolo, S.; Franz, S.; Arab, H.; Bestetti, M.; Falletta, E.; Mascolo, G. Degradation of emerging organic pollutants in wastewater effluents by electrochemical photocatalysis on nanostructured $\mathrm{TiO}_{2}$ meshes. Water Res. 2019, 164, 114920. [CrossRef]

39. Collivignarelli, M.C.; Abbà, A.; Carnevale Miino, M.; Arab, H.; Bestetti, M.; Franz, S. Decolorization and biodegradability of a real pharmaceutical wastewater treated by $\mathrm{H}_{2} \mathrm{O}_{2}$-assisted photoelectrocatalysis on $\mathrm{TiO}_{2}$ meshes. J. Hazard. Mater. 2020, 387, 121668. [CrossRef]

40. Franz, S.; Falletta, E.; Arab, H.; Murgolo, S.; Bestetti, M.; Mascolo, G. Degradation of Carbamazepine by Photo(electro)catalysis on Nanostructured $\mathrm{TiO}_{2}$ Meshes: Transformation Products and Reaction Pathways. Catalysts 2020, 10, 169. [CrossRef]

41. Shard, A.G. Detection limits in XPS for more than 6000 binary systems using Al and Mg K $\alpha$ X-rays. Surf. Interface Anal. 2014, 46, 175-185. [CrossRef] 
42. Energy Dispersive X-ray Spectroscopy tutorial EAG Laboratories. Available online: https://www.eag.com/ techniques/spectroscopy/energy-dispersive-X-ray-spectroscopy-eds/ (accessed on 20 March 2020).

43. Berti, G.; Calloni, A.; Brambilla, A.; Bussetti, G.; Duò, L.; Ciccacci, F. Direct observation of spin-resolved full and empty electron states in ferromagnetic surfaces. Rev. Sci. Instrum. 2014, 85, 073901. [CrossRef] [PubMed]

44. Galenda, A.; Visentin, F.; Gerbasi, R.; Battiston, S.; Habra, N. El Effective and Low-Cost Synthesis of Sulphur-Modified $\mathrm{TiO}_{2}$ Nanopowder with Improved Photocatalytic Performances in Water Treatment Applications. Water Air Soil Pollut. 2017, 228, 416. [CrossRef]

45. Spurr, R.A.; Myers, H. Quantitative analysis of anatase-rutile mixtures with an X-ray diffractometer. Anal. Chem. 1957, 29, 760-762. [CrossRef]

46. Tauc, J. Optical properties and electronic structure of amorphous Ge and Si. Mater. Res. Bull. 1968, 3, 37-46. [CrossRef]

47. Saha, N.C.; Tompkins, H.G. Titanium nitride oxidation chemistry: An x-ray photoelectron spectroscopy study. J. Appl. Phys. 1992, 72, 3072-3079. [CrossRef]

48. Biesinger, M.C.; Lau, L.W.M.; Gerson, A.R.; Smart, R.S.C. Resolving surface chemical states in XPS analysis of first row transition metals, oxides and hydroxides: Sc, Ti, V, Cu and Zn. Appl. Surf. Sci. 2010, 257, 887-898. [CrossRef]

49. Topalian, Z.; Niklasson, G.A.; Granqvist, C.G.; Österlund, L. Spectroscopic Study of the Photofixation of $\mathrm{SO}_{2}$ on Anatase $\mathrm{TiO}_{2}$ Thin Films and Their Oleophobic Properties. ACS Appl. Mater. Interfaces 2012, 4, 672-679.

50. Randeniya, L.K.; Murphy, A.A.B.; Plumb, A.I.C. A study of S-doped $\mathrm{TiO}_{2}$ for photoelectrochemical hydrogen generation from water. J. Mater. Sci. 2008, 43, 1389-1399. [CrossRef]

51. Ohno, T.; Akiyoshi, M.; Umebayashi, T.; Asai, K.; Mitsui, T.; Matsumura, M. Preparation of S-doped $\mathrm{TiO}_{2}$ photocatalysts and their photocatalytic activities under visible light. Appl. Catal. A Gen. 2004, 265, 115-121. [CrossRef]

52. Chiarello, G.L.; Zuliani, A.; Ceresoli, D.; Martinazzo, R.; Selli, E. Exploiting the Photonic Crystal Properties of $\mathrm{TiO}_{2}$ Nanotube Arrays to Enhance Photocatalytic Hydrogen Production. ACS Catal. 2016, 6, 1345-1353. [CrossRef]

53. Murata, Y.; Fukuta, S.; Ishikawa, S.; Yokoyama, S. Photoelectrochemical properties of $\mathrm{TiO}_{2}$ rutile microalloyed with $4 \mathrm{~d}$ and $5 \mathrm{~d}$ transition elements. Sol. Energy Mater. Sol. Cells 2000, 62, 157-165. [CrossRef]

54. Seetharaman, A.; Sivasubramanian, D.; Gandhiraj, V.; Rao Soma, V. Tunable Nanosecond and Femtosecond Nonlinear Optical Properties of C-N-S-Doped $\mathrm{TiO}_{2}$ Nanoparticles. J. Phys. Chem. C 2017, 121, 24192-24205. [CrossRef]

55. Khan, M.M.; Ansari, S.A.; Pradhan, D.; Ansari, M.O.; Han, D.H.; Lee, J.; Cho, H. Band gap engineered $\mathrm{TiO}_{2}$ nanoparticles for visible light induced photoelectrochemical and photocatalytic studies. J. Mater. Chem. A 2014, 2, 637-644. [CrossRef]

56. Matsushima, S.; Takehara, K.; Yamane, H.; Yamada, K.; Nakamura, H.; Arai, M.; Kobayashi, K. First-principles energy band calculation for undoped and S-doped $\mathrm{TiO}_{2}$ with anatase structure. J. Phys. Chem. Solids 2007, 68, 206-210. [CrossRef]

57. Lin, Y.M.; Jiang, Z.Y.; Zhu, C.Y.; Hu, X.Y.; Zhang, X.D.; Fan, J. Visible-light photocatalytic activity of Ni-doped $\mathrm{TiO}_{2}$ from ab initio calculations. Mater. Chem. Phys. 2012, 133, 746-750. [CrossRef]

58. Sun, T.; Fan, J.; Liu, E.; Liu, L.; Wang, Y.; Dai, H.; Yang, Y.; Hou, W.; Hu, X.; Jiang, Z. Fe and Ni co-doped TiO 2 nanoparticles prepared by alcohol-thermal method: Application in hydrogen evolution by water splitting under visible light irradiation. Powder Technol. 2012, 228, 210-218. [CrossRef]

59. Serpone, N.; Pelizzetti, E. Photocatalysis: Fundamentals and Applications; Wiley: New York, NY, USA, 1989; ISBN 0471626031.

(C) 2020 by the authors. Licensee MDPI, Basel, Switzerland. This article is an open access article distributed under the terms and conditions of the Creative Commons Attribution (CC BY) license (http://creativecommons.org/licenses/by/4.0/). 